\title{
2D and 3D numerical simulation of the wind-rotor/nacelle interaction in an atmospheric boundary layer
}

\author{
Khaled Ameur ${ }^{1}$ \\ Christian Masson ${ }^{1}$ \\ Peter J. Eecen \\ ${ }^{1}$ Canada Research Chair on Nordic Environment Aerodynamics of Wind Turbines \\ Published in: Journal of Wind Engineering and Industrial Aerodynamics, \\ Vol.99, Issue 8, August, 2011, pp.833-844
}




\title{
2D and 3D numerical simulation of the wind-rotor/nacelle interaction in an atmospheric boundary layer
}

\author{
Khaled Ameur ${ }^{\mathrm{a}, *}$, Christian Masson $^{\mathrm{a}}$, Peter J. Eecen ${ }^{\mathrm{b}}$ \\ ${ }^{a}$ Canada Research Chair on Nordic Environment Aerodynamics of Wind Turbines, École de Technologie Supérieure, Département de Génie Mécanique, \\ 1100 Rue Notre-Dame Ouest, Montréal, Québec, Canada H3C 1 K3 \\ ${ }^{\mathrm{b}}$ The Energy Research Centre of the Netherlands, ECN Wind Energy, Westerduinweg 3, 1755 LE Petten, The Netherlands
}

\section{A R T I C L E I N F O}

Article history:

Received 24 March 2010

Received in revised form 20 May 2011

Accepted 6 June 2011

Available online 24 June 2011

Keywords:

Wind turbine

Nacelle anemometry

2D 3D computations

RANS

Atmospheric boundary layer

\begin{abstract}
A B S T R A C T
Two-dimensional axisymmetric and three-dimensional steady turbulent flow computations around two horizontal-axis wind turbines (Nordex N80 and Jeumont J48) are carried out to investigate the wind-rotor/nacelle interaction and quantify its effects on the wind speed at the nacelle anemometry. The actuator disk concept has been used to model the action of the blades. For both turbines, the geometry of the nacelle was reproduced as faithfully as possible. The terrain was represented by an appropriate law of the wall to account for roughness with particular attention paid to the boundary conditions in order to reproduce the neutral atmospheric boundary layer. The calculated velocity field in the vicinity of the nacelle exhibits good agreement with available experimental data. The results also show that for a complex nacelle geometry, like that of the $\mathrm{N80}$, a three-dimensional calculation is necessary to obtain a good prediction of the velocity field in the near wake. The hub height effect is evaluated for the J48 by raising the nacelle from a height of 36 to $60 \mathrm{~m}$. No significant impact is noted on the ratio nacelle wind speed/freestream wind speed.
\end{abstract}

(c) 2011 Elsevier Ltd. All rights reserved.

\section{Introduction}

The nacelle-mounted anemometer on horizontal-axis wind turbines is primarily used for power regulation. However, many researchers recognize that the data from this anemometer could potentially be used for other purposes, such as power site calibration and performance testing (Antoniou and Pedersen, 1997; Hunter et al., 2001; Smith et al., 2002), which has prompted the development of an international committee draft standard, IEC CD61400-12-2 (2008). The usefulness of nacelle anemometry in such applications depends critically on the knowledge of the relationship between the measured wind speed at the nacelle anemometer $\left(U_{\text {nacelle }}\right)$ and freestream wind velocity $\left(U_{\infty}\right)$. Multiple factors (Frandsen et al., 2009) influence the nacelle anemometer measurement yielding a complex relationship between $U_{\text {nacelle }}$ and $U_{\infty}$. The wake from the rotating blades and the shape of the nacelle are among the most important factors and are discussed in this paper.

Although many studies have been published on the subject of horizontal-axis wind turbine wakes (Crespo et al., 1999; Vermeer et al., 2003), few were interested in the immediate vicinity of the nacelle; in most cases, the nacelle was neglected or approximated

\footnotetext{
* Corresponding author. Fax: +1 5143968530.

E-mail address: k-ameur@hotmail.com (K. Ameur).
}

with a simple pressure drop (El Kasmi and Masson, 2008). The complete representation of the nacelle and rotor rotation in the grid is an approach that requires large computing resource. Zahle and Sørensen (2011) with such an approach computed a 3D turbulent flow close to a $500 \mathrm{~kW}$ wind turbine in a uniform inflow. They showed the importance of the yaw and tilt on the nacelle anemometry. A comparison between steady and unsteady calculation showed also that the stationary case, far from being realistic, can capture most of the flow characteristics near the nacelle. The actuator disk method, which is a simplification in the representation of the rotor, was intensively used by Masson and his team (Smaili and Masson, 2004; Masson and Smaili, 2006) to analyze the rotor/ nacelle interaction for two-dimensional axisymmetric cases. They were able to demonstrate the importance of several parameters on the flow near the nacelle, such as the cylindrical section at the blade root. The transition to a three-dimensional calculation using more realistic boundary conditions to simulate the atmospheric boundary layer seems a logical extension of this work. Herein, 2D-axisymmetric and 3D numerical simulations of flow around two horizontal-axis wind turbines are presented: the Nordex N80 and the Jeumont J48. The simulations were performed by resolving the RANS equations over the whole computational domain with two turbulence models: $k-\varepsilon$ and $k-\omega$ sst. The geometry of the nacelle was represented as accurately as possible and the rotor was approximated by the actuator disk concept. To correctly model the influence of rough terrain, an appropriate law of the wall was used. 
All calculations were performed with the finite volume method using the commercial software Fluent 6.3.

\section{Mathematical model}

\subsection{Governing equations}

The wind flow is governed by the incompressible steady Navier-Stokes equations, which are derived from the principles of conservation of mass and momentum. After applying the Reynolds decomposition and using the concept of turbulent viscosity $\left(\mu_{t}\right)$, the system of equations in integral form is

$\int_{A} u_{i} n_{i} d A=0$,

$\int_{A} \rho u_{i} u_{j} n_{j} d A=-\int_{A} p \delta_{i j} n_{j} d A+\int_{A} \tau_{i j} n_{j} d A+\int_{A_{\text {disk }}}\left(f_{n}\right)_{i} d A$,

where $\rho$ is the air density, $u_{i}$ is the velocity vector $(u, v, w)$ and the Reynolds tensor $\tau_{i j}$ is given by

$\tau_{i j}=\left(\mu+\mu_{t}\right)\left(\frac{\partial u_{i}}{\partial x_{j}}+\frac{\partial u_{j}}{\partial x_{i}}\right)$,

where $\mu$ is the dynamic viscosity and $x_{i}$ is the Cartesian coordinate $(x, y, z)$

These equations are applied to a control volume $V$ bounded by a surface $A$. $n_{j}$ is the unit vector normal to $A$ and pointing out of $V$. $\delta_{i j}$ is the Kronecker delta. The unknowns of the system are the three velocity components $u_{i}$, the pressure $p$ and the turbulent viscosity.

The integral $\int\left(f_{n}\right)_{i} d A$ represents the effect of the rotor on the flow. It is inserted into the balance for momentum conservation as a source term to be applied on the surface of the actuator disk $A_{\text {disk }}$. The time average of this force is evaluated by two different techniques depending on the availability of aerodynamic characteristics of the wind turbine blades. More details are given in the following paragraphs.

\subsection{Turbulence model}

To close the above system, the standard two equation $k-\varepsilon$ model of Launder and Spalding (1974) was used for most calculations of this paper. It is a popular and robust turbulence model that has been thoroughly tested in the wind energy field (Snel, 1998; Vermeer et al., 2003). However, it has some limitations related to low Reynolds number effects near the wall and regions of separated flow (Wilcox, 1993b). The poor representation of the flow near the wall requires the use of flow empirical corrections.

The turbulent viscosity is linked to the turbulent kinetic energy $k$ and turbulent dissipation rate $\varepsilon$ by

$\mu_{t}=C_{\mu} \rho \frac{k^{2}}{\varepsilon}$,

where $C_{\mu}$ is a constant.

The equations for $k$ and $\varepsilon$ are given by

$\int_{A} \rho k u_{i} n_{i} d A=\int_{V}\left(P_{k}-\rho \varepsilon\right) d V+\int_{A} \Gamma_{k} \frac{\partial k}{\partial x_{i}} n_{i} d A$,

$\int_{A} \rho \varepsilon u_{i} n_{i} d A=\int_{V}\left(C_{\varepsilon_{1}} \frac{\varepsilon}{k} P_{k}-C_{\varepsilon_{2}} \rho \frac{\varepsilon^{2}}{k}\right) d V+\int_{A} \Gamma_{\varepsilon} \frac{\partial \varepsilon}{\partial x_{i}} n_{i} d A$,

The production of kinetic energy is evaluated with,

$P_{k}=\mu_{t}\left(\frac{\partial u_{i}}{\partial x_{j}}+\frac{\partial u_{j}}{\partial x_{i}}\right) \frac{\partial u_{i}}{\partial x_{j}}$, and diffusion coefficients are evaluated with,

$\Gamma_{k}=\mu+\frac{\mu_{t}}{\sigma_{k}} \quad$ and $\quad \Gamma_{\varepsilon}=\mu+\frac{\mu_{t}}{\sigma_{\varepsilon}}$.

The model constants proposed by Crespo et al. (1985) and Migoya et al. (2007) were used. These coefficients (Table 1) were calibrated for simulating the neutral atmospheric boundary layer.

For comparison, a second turbulence model, the $k-\omega$ sst of Menter (1994), was also used. One of the advantages of this model is a better wall treatment. Indeed, using damping functions, this model links the standard $k-\omega$ of Wilcox (1993a) close to the wall to the standard $k-\varepsilon$ away from the wall. For both models, $\mu_{t}$ and $k$ are evaluated in the same way. However, the use of $\omega=\varepsilon / k$ will generate an extra term in the equation for the dissipation rate compared to the $k-\varepsilon$ model.

To compare with the standard wall function (SWF), a calculation through the viscous sub-layer was also made with an enhanced wall treatment (EWT). The disadvantage of this approach is that it requires a very fine mesh. It should be noted that at the ground surface of the computational domain, another treatment is recommended in which the details are discussed below.

\subsection{Boundary conditions}

To properly reproduce the neutral atmospheric boundary layer $(A B L)$, special attention was paid to boundary conditions and the representation of the ground. In fact, commercial codes such as Fluent and CFX have difficulty properly modeling the ABL, as shown by Hargreaves and Wright (2007). Even without obstacles, the inlet conditions can be difficult to maintain along the field. To counter this weakness, the recommendations of Richard and Hoxey (1993) were adopted, consisting of a specified velocity and turbulence profile at the entrance of the domain, a special law of the wall at the ground, and imposition of a shear stress at the top boundary. Here, this last condition was replaced by imposing a velocity. In what follows, these conditions are referred to as the $\mathrm{R}-\mathrm{H}$ conditions. The boundary conditions for 3D- and 2D-axisymmetric simulations are summarized in Fig. 1. More details about the $3 \mathrm{D}$ boundary conditions are presented below.

\subsubsection{Inlet}

Velocity and turbulent profiles were imposed at the inlet. The logarithmic velocity profile (Richards and Hoxey, 1993) accurately represents a neutral atmospheric boundary layer and is given by

$u=\frac{u^{*}}{\kappa} \ln \left(\frac{z+z_{0}}{z_{0}}\right)$

where $z_{0}$ is the roughness height, $u^{*}$ is the friction velocity and $\kappa$ is the von Karman constant whose value is 0.42 . The turbulent kinetic energy and its dissipation rate are given by

$k=\frac{u^{* 2}}{\sqrt{C_{\mu}}}$

$\varepsilon=\frac{u^{* 3}}{\kappa\left(z+z_{0}\right)}$

\section{Table 1}

Turbulence constants of the $k-\varepsilon$ turbulence model.

\begin{tabular}{ccccc}
\hline$\sigma_{k}$ & $\sigma_{\varepsilon}$ & $C_{\varepsilon_{1}}$ & $C_{\varepsilon_{2}}$ & $C_{\mu}$ \\
\hline 1.0 & 1.3 & 1.176 & 1.92 & 0.0333 \\
\hline
\end{tabular}




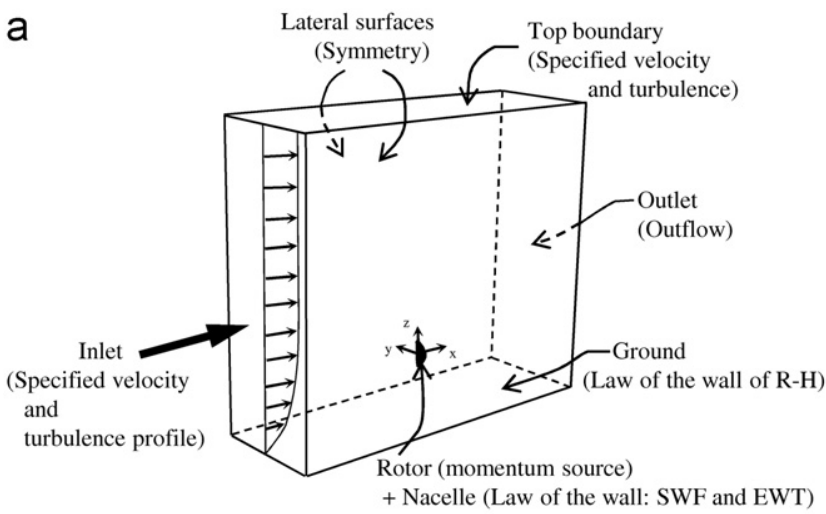

b

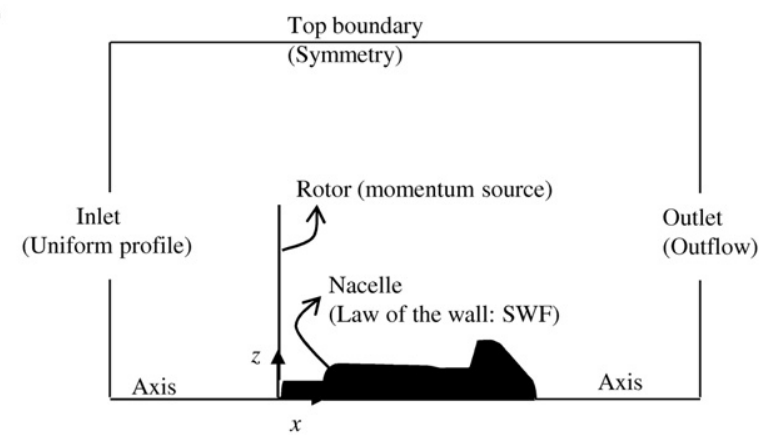

Fig. 1. Computational domain with boundary conditions for (a) $3 D$ and (b) 2D-axisymmetric simulations.

The friction velocity is estimated from,

$u^{*}=\frac{\kappa U_{r e f}}{\ln \left(\left(z_{h u b}+z_{0}\right) / z_{0}\right)}$,

where $U_{\text {ref }}$ is the reference velocity at the hub height, $z_{\text {hub }}$. For flat terrain and without obstacles, $U_{r e f}$ is assumed to be equal to freestream wind velocity. These inlet conditions combined with the constants of Crespo represent a solution of the model equations.

\subsubsection{Lateral surfaces}

The two lateral surfaces were treated as a symmetry condition, which is to consider the flux of all quantities across this area as zero $(\partial / \partial y(u, w, p, k, \varepsilon)=0)$ and zero transverse velocity $(v=0)$.

\subsubsection{Outlet}

The outflow condition was required for the outlet. Fluxes of all quantities in the normal direction at the outlet plane are assumed to be zero $(\partial / \partial x(u, v, w, p, k, \varepsilon)=0)$. No data is imposed on this boundary; everything is extrapolated from inside the volume. This condition is appropriate when the flow is close to a fullydeveloped condition.

\subsubsection{Top boundary}

The imposition of a shear stress at the top boundary (Richards and Hoxey, 1993; Hargreaves and Wright, 2007) of the domain is important to be able to compensate the loss of momentum at the ground level and to drive the flow. For simplicity, an axial unidirectional velocity (Prospathopoulos and Voutsinas, 2006; Brodeur and Masson, 2008) and turbulent quantities were derived from the inlet profiles and applied to this boundary.

\subsubsection{Treatment of the nacelle wall}

In a turbulent flow, performing a calculation to the wall can be very expensive. Furthermore, the foundations upon which some turbulence models are based may no longer be valid, such as the presence of an adverse pressure gradient in the case of the $k-\varepsilon$ model. These weaknesses are often avoided by the use of empirical models.

In the majority of our calculations, where the turbulence was modeled by $k-\varepsilon$, the semi-empirical standard functions of Launder and Spalding (1974) were used near the nacelle walls with some Fluent (2005) specific features. This treatment using the SWF to evaluate the characteristics of the main flow and turbulent quantities is explained in the following sections.

\subsubsection{Momentum. For momentum, two zones can be} distinguished.

- In the logarithmic zone $\left(11.225<y^{*}<300\right)$, the following relation is used for momentum,

$U^{*}=\frac{1}{\kappa} \ln \left(E y^{*}\right)$,

and

$y^{*}=\frac{\rho C_{\mu}^{1 / 4} k_{1}^{1 / 2} y_{1}}{\mu}$,

where $U^{*}$ and $y^{*}$ are dimensionless values of, respectively, $u$ and $y$. The index 1 indicates the centroid of the first cell adjacent to the wall. $E$ is an empirical constant equal to 9.793 .

- Where the mesh is fine $\left(y^{*}<11.225\right)$, in the viscous sub-layer, the speed obeys the linear relation,

$U^{*}=y^{*}$.

2.3.5.2. Turbulent kinetic energy. Close to the nacelle wall (5) remains valid for the evaluation of $k$ but the production term becomes,

$P_{k}=\frac{\tau_{w}^{2}}{\kappa \rho C_{\mu}^{1 / 4} k_{1}^{1 / 2} y_{1}}$.

As the nacelle wall is considered to be smooth, then the shear stress $\tau_{w}$ does not include any term assessing the roughness and is given by

$\tau_{w}=\frac{C_{\mu}^{1 / 4} k_{1}^{1 / 2}}{(1 / \kappa) \ln (E / \kappa)}$.

2.3.5.3. Dissipation rate of turbulent kinetic energy. In the cell adjacent to wall, $\varepsilon$ is calculated with,

$\varepsilon_{1}=\frac{C_{\mu}^{3 / 4} k_{1}^{3 / 2}}{\kappa y_{1}}$

\subsubsection{Rotor}

The actuator disk, as implemented by Sørensen and Myken (1992), allows for the gross effects of the rotor to be captured with an appreciable decrease in computing time as the blade geometry was not resolved. The rotor was modeled by a permeable surface where axial and tangential forces were applied as source terms in the momentum equations. These forces were evaluated by the blade element momentum (BEM) theory, which required the knowledge of the aerodynamic characteristics of the airfoil constituting the blade. In this work, this approach was simplified using the fan model in Fluent. It is a feature that allows specification of a pressure jump on the surface representing the rotor. However, tangential forces were neglected due to unavailable detailed aerodynamic characteristics for one of the two wind turbines studied. 
The calculations in this study include two wind turbines: the Jeumont J48 and Nordex N80. The characteristics of these two wind turbines are summarized in Table 2. Unlike the Nordex, the geometry of the Jeumont nacelle is highly symmetrical about the axis of rotation of the rotor. The Nordex N80 calculations were validated with experimental results obtained from the Energy research Center of the Netherlands (ECN) in its research wind farm consisting of five $2.5 \mathrm{MW}$ wind turbines (Eecen and Verhoef, 2007) on a site with an estimated roughness height of $z_{0}=0.05 \mathrm{~m}$.

As the geometric and aerodynamic blade properties of the Jeumont turbine are known and not those of the N80, two different approaches were used to assess the pressure jump associated with the rotor.

2.3.6.1. Pressure jump: Jeumont J48. For the wind turbine J48 BEM theory was applied for the entire surface of the actuator disk to assess the pressure jump. For a given radial position $(r)$, after computing local angles of attack and evaluating the aerodynamic characteristics from tabulated airfoil coefficients, the pressure jump is calculated by

$\Delta p=\frac{1}{2} \rho c V_{r e l} \frac{B}{2 \pi r}\left(V_{w} C_{l}+V_{u} C_{d}\right)$,

where $B$ is the number of turbine blades, $c$ is the chord, $C_{l}$ and $C_{d}$ are the lift and drag coefficients, respectively. Velocities are given by

$V_{\text {rel }}=\sqrt{V_{u}^{2}+V_{w}^{2}}, \quad V_{w}=\Omega r, \quad V_{u}=\frac{U_{u p}+U_{\text {down }}}{2}$,

$U_{u p}$ and $U_{\text {down }}$ represent the axial velocity just upstream and downstream of the actuator disk, respectively. $\Omega$ is the rotational speed of the rotor.

2.3.6.2. Pressure jump: Nordex N80. The airfoil characteristic of the Nordex N80 are not publicly available, hence the following procedure was adopted:

Two areas on the disk were considered (see Fig. 2),

- an external area representing the surface swept by the blade where the pressure was estimated by the experimental axial thrust coefficient $\left(C_{T_{\exp }}\right)$,

$$
\Delta p=\frac{1}{2} \rho U_{\infty}^{2} C_{T_{\exp }}
$$

- an internal area representing the area swept by the cylindrical part of the blades (blade root), where the pressure jump imposed was evaluated by relation (19). In this case, $c$ is the diameter of the cylinder forming the base of the blade. As a circular cross section does not generate lift, $C_{l}$ is zero. The drag coefficient was evaluated using an empirical relation, which depends on the local Reynolds number (Masson and Smaili, 2006). This relation is valid for an infinite cylinder but correction for the finite length of the blade root was applied.

\subsubsection{Ground surface}

With the commercial code Fluent, taking into account the roughness of the ground is quite difficult. Indeed, the representation of the roughness in this code is based on that of the internal flows of Cebeci and Bradshaw (1977). The approach of treating the nacelle wall in Section 2.3.5 remains valid, except for the evaluation of shear stress, which is done by

$\tau_{w}=\frac{C_{\mu}^{1 / 4} k_{1}^{1 / 2}}{(1 / \kappa) \ln (E / \kappa)-\Delta B}$,

$\Delta B$ is a function based on the equivalent sand-grain roughness of the surface. For a smooth hydrodynamic regime $\Delta B$ is zero and when it is completely rough, it takes the following form:

$\Delta B=\frac{1}{\kappa} \ln \left(1+C_{S} K_{S}^{+}\right)$,

with,

$K_{S}^{+}=\frac{\rho C_{\mu}^{1 / 4} k_{1}^{1 / 2} K_{S}}{\mu}$,

where $C_{S}$ and $K_{S}$ are constants to be chosen to set a certain roughness.

This approach relies on the use of two parameters $\left(C_{S}\right.$ and $\left.K_{S}\right)$ whose relation with the roughness $z_{0}$ is not clear although several authors tried to build relations between these variables (Gasset et al., 2005). Unfortunately, this approach has other disadvantages, such as the inability to model a surface with high roughness (Blocken et al., 2007).

As a remedy, the law of the wall proposed by Richards and Hoxey (1993) was chosen. This law imposes on the first cell adjacent to the ground, an axial velocity, a turbulent kinetic energy and a dissipation rate evaluated by the Eqs. (9)-(11), where the friction velocity is estimated from the second cell adjacent to the ground surface using the following relation:

$u^{*}=\frac{\kappa u_{2}}{\ln \left(\left(z_{2}+z_{0}\right) / z_{0}\right)}$

The reference height $z_{2}$ is the vertical position of the second cell with the associated axial velocity $u_{2}$.

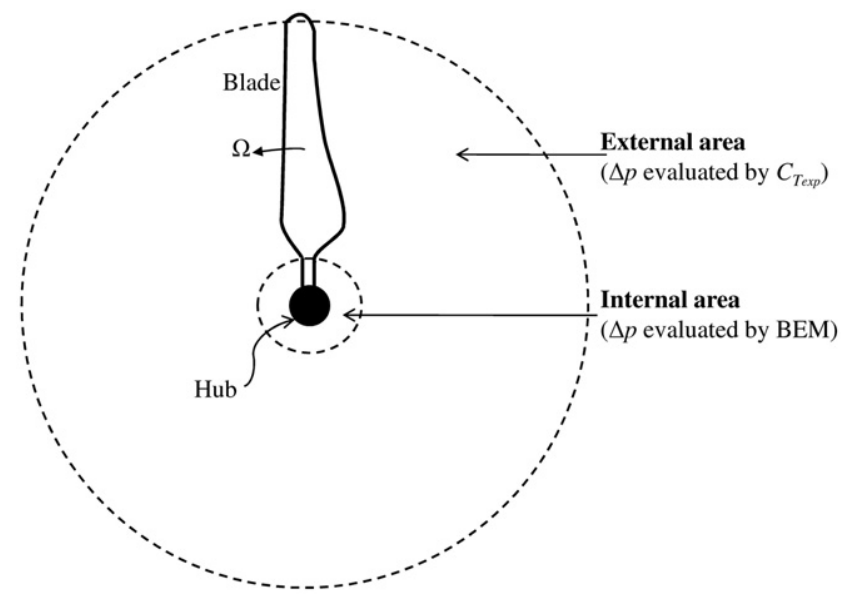

Fig. 2. Subdivision of the actuator disk into two zones for the Nordex N80 rotor

Table 2

Main characteristics of wind turbines used in this study.

\begin{tabular}{|c|c|c|c|c|c|c|c|c|}
\hline Wind turbine & Number of blades & Power (kW) & Blade radius (m) & Hub height (m) & $\mathrm{RPM}(\mathrm{tr} / \mathrm{min})$ & Pitch angle (deg.) & Tilt angle (deg.) & Coning angle (deg.) \\
\hline N80 & 3 & 2500 & 38.8 & 80 & $10.9-19.1$ & 10 & 5 & 2 \\
\hline $\mathrm{J} 48$ & 3 & 750 & 24 & 46 & $9-25.3$ & 10 & 0 & 0 \\
\hline
\end{tabular}




\section{Numerical model}

\subsection{Numerical method}

The finite volume method, under Fluent, was used to solve the governing equations. This resolution was sequential and the treatment of pressure/velocity coupling was handled by the SIMPLE algorithm. The diffusion terms were discretized by a centered scheme of second order. For convective terms, a firstorder upwind scheme was used. A scheme of higher order would have been advisable to reduce the size of the grid but the use of such a scheme has led to convergence problems. A grid convergence study was done to estimate the numerical error.

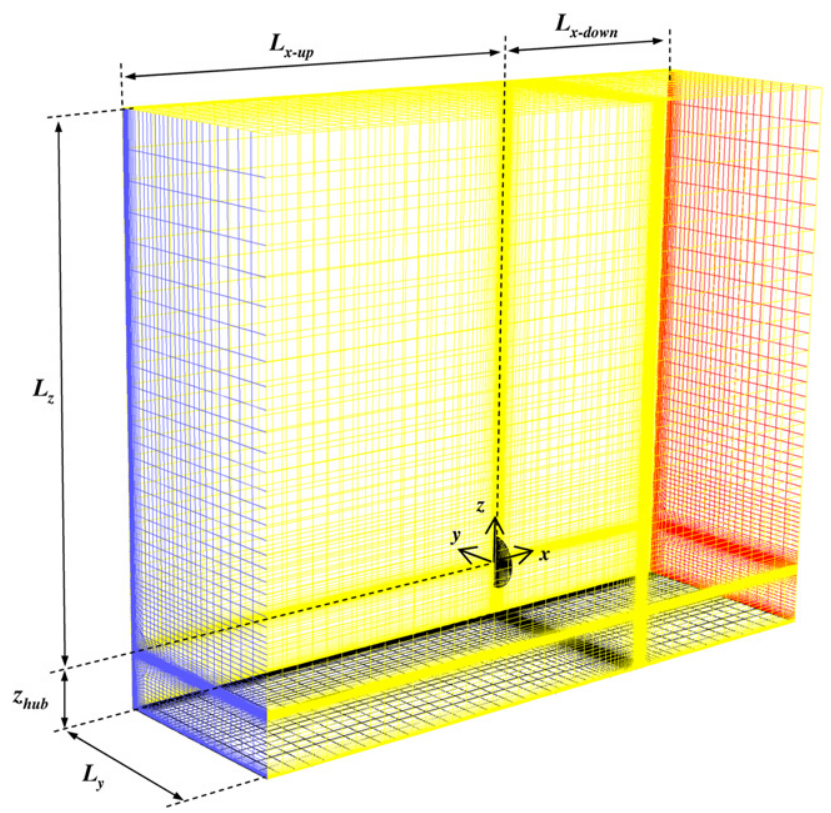

Fig. 3. 3D computational domain.

\subsection{Mesh}

The 3D computational domain has the shape of a rectangular parallelepiped (Fig. 3). The mesh consists mostly of hexahedral cells; close to the nacelle and rotor some deformations are present but remain acceptable (Fig. 4). Hexahedral cells provide a much better solution with smaller discretization error compared to tetrahedral cells as shown by Hefny and Ooka (2009). To save on the overall number of cells, only half of the nacelle and rotor have been considered, yielding an average of $1.1 \times 10^{6}$ cells. When using the EWT, this number exceeds $2 \times 10^{6}$ due to grid refinement at the wall. The tower has been neglected.

The 2D-axisymmetric mesh was constructed from a simple vertical cut through the axis of rotation in the $3 \mathrm{D}$ computational domain.

The dimensions of the computational domain have been based on the result of a grid dependence study using the N80 turbine with the rotor-on and a wind speed at hub height of $20 \mathrm{~m} / \mathrm{s}$ (Fig. 5). The domain height $\left(L_{z}\right)$ and the upstream fetch $\left(L_{x-u p}\right)$ have the greatest impact on the solution, hence the choice of the dimensions of the domain: $L_{z}=8.75 D, L_{y}=3.75 D, L_{x-u p}=7.5 \mathrm{D}$ and $L_{x \text {-down }}=3.75 D$, with $D$ being the diameter of the rotor.

\section{Error analysis}

The quality of a numerical study can be evaluated by estimating the discretization error. One of the most popular methods for evaluating the truncation error is through the grid convergence index (GCI) (Roache, 1994). This technique has several variants but, for the present work, the approach outlined by Celik et al. (2008) was used.

The grid was refined by a factor of 2.2 to evaluate the $\mathrm{GCI}$ (see Table 3). Table 4 summarizes the results of the grid convergence study. Simulations were carried out for both a N80 rotor-off and rotor-on with three different velocities at the inlet $\left(U_{\infty}=5,15\right.$ and $20 \mathrm{~m} / \mathrm{s}$ ). Overall, the GCI for the fine mesh was less than $13 \%$ and drops to $5.53 \%$ for simulations with the rotoron and a wind velocity of $20 \mathrm{~m} / \mathrm{s}$. In the case in which the rotor is a

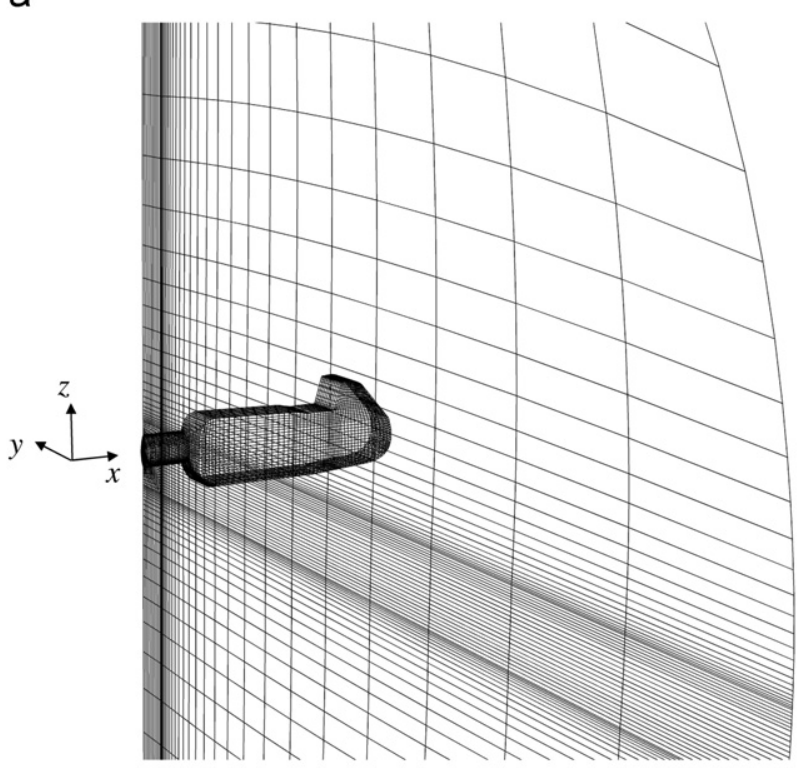

b

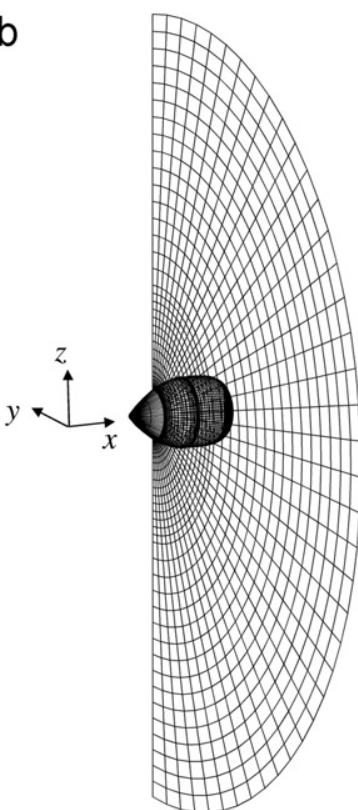

Fig. 4. Details in the vicinity of the nacelle and rotor for (a) N80 and (b) J48. 


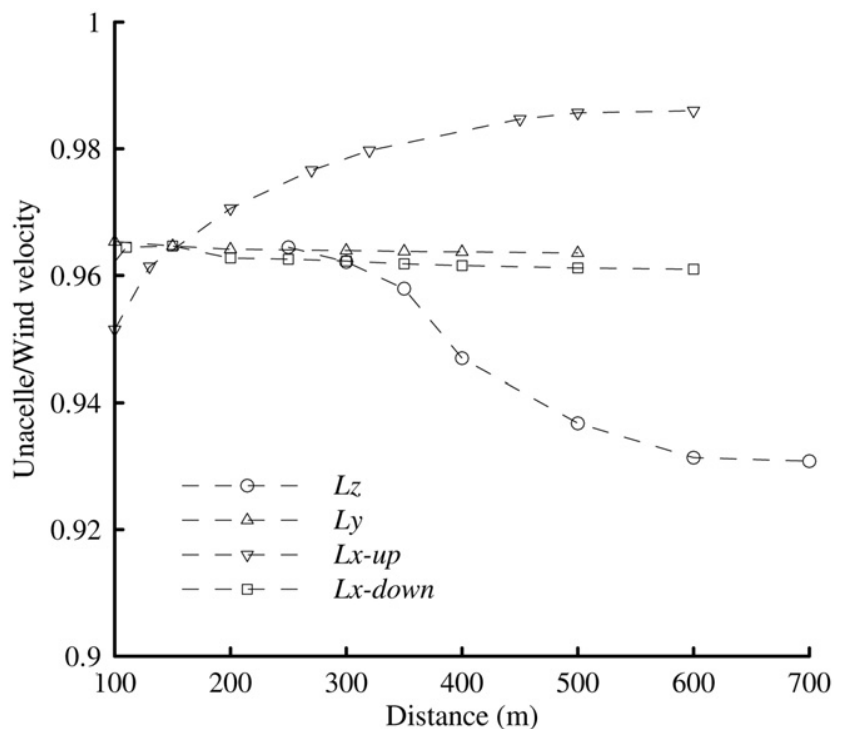

Fig. 5. Effect of domain size on calculated anemometer wind speed (N80, rotor-on, $C_{T_{\exp }}=0.128$ and $U_{\infty}=20 \mathrm{~m} / \mathrm{s}$ ).

Table 3

Mesh used and refinement factors.

\begin{tabular}{llc}
\hline Mesh & Cells number $\left(10^{5}\right)$ & $r$ \\
\hline $1-2$ & $2.39-5.36$ & 1.3 \\
$2-3$ & $5.36-11.79$ & 1.3 \\
\hline
\end{tabular}

Table 4

Numerical errors obtained by the study of mesh refinement.

\begin{tabular}{lcccccc}
\hline Rotor & $U_{\infty}(\mathrm{m} / \mathrm{s})$ & $C_{T_{\exp }}$ & $e_{a}^{1-2}(\%)$ & $e_{a}^{2-3}(\%)$ & $G C I^{1-2}(\%)$ & $G C I^{2-3}(\%)$ \\
\hline \multirow{2}{*}{ Rotor-off } & 5 & & 9.07484 & 5.91764 & 16.52192 & 10.77384 \\
& 15 & & 9.08940 & 6.20744 & 18.60528 & 12.70615 \\
& 20 & & 9.09244 & 6.22891 & 18.76384 & 12.85444 \\
Rotor-on & 5 & 0.793 & 7.28776 & 4.70617 & 13.5909 & 8.77651 \\
& 15 & 0.305 & 7.86614 & 4.58888 & 11.42635 & 6.66558 \\
& 20 & 0.128 & 8.12884 & 4.42429 & 10.16219 & 5.53099 \\
\hline
\end{tabular}

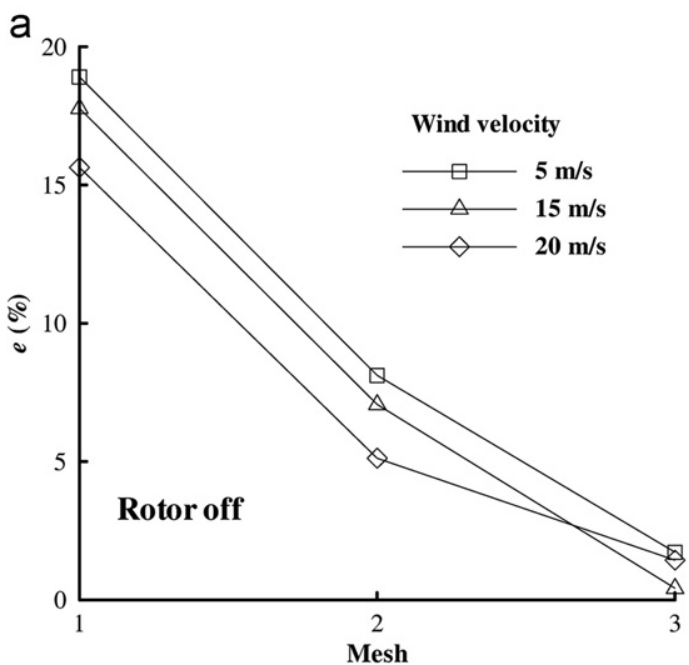

stopped, the $\mathrm{GCI}$ increases with $U_{\infty}$; this tendency was reversed when the turbine is in operation. Finally, the values of GCI were almost twice that the approximate relative errors $\left(e_{a}\right)$ for rotor-off and slightly less for rotor-on.

The relative error $(e)$ was also calculated for the three meshes (1, 2 and 3 ) described above by comparing with experimental values. The simulations used in the assessment of GCI were retained and the relative error is given by

$e=\left|\frac{\phi_{\text {num }}-\phi_{\text {exp }}}{\phi_{\exp }}\right|$,

$\phi_{\text {num }}$ is the calculated value and $\phi_{\text {exp }}$ is the experimental value. In this case, $\phi$ represents the velocity at the nacelle anemometer position. As shown in Fig. 6, the relative error decreases with mesh refinement for the full range of wind speeds simulated $(5,15$ and $20 \mathrm{~m} / \mathrm{s})$. The finest mesh had an associated error of about $2 \%$ and this error further decreased if the wind turbine is stopped.

Lastly, the sensitivity of the mesh on the nacelle drag is presented in Table 5 for wind speed of $15 \mathrm{~m} / \mathrm{s}$. For the case of the rotor-off, the computed values were of the same order of magnitude as that of a simple empirical calculation (848 N) where the nacelle was approximated to a cube with a drag coefficient of 1.02 (Hoerner, 1965). Between the finer mesh 3 and the mesh 2 the variation of the drag was only $1 \%$ for rotor-off and $3 \%$ for rotor-on. The results also show that an operational rotor involved a larger drag on the nacelle than for a stopped wind turbine.

\section{Results}

Unless otherwise stated, all 3D calculations were performed with the standard $k-\varepsilon$ turbulence model using the SWF for the nacelle wall and the $\mathrm{R}-\mathrm{H}$ treatment for all other boundary conditions.

\subsection{Wind turbine Nordex N80}

Experimental data for the N80 was used to validate the proposed model. Fig. 7 shows a comparison between measurements, 2D-axisymmetric and 3D calculations of the wind velocity at the nacelle anemometer position for various incoming wind speeds. The relationship between these two velocities, also called the nacelle transfer function, was represented in the format recommended by the committee draft international standard (IEC CD61400-12-2, 2008).

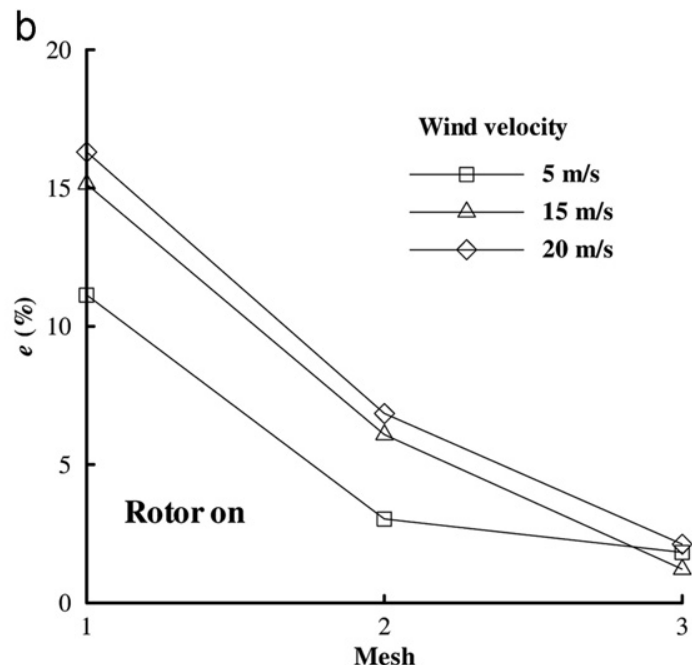

Fig. 6. Relative error with respect to experimental values for (a) rotor-off and (b) rotor-on. 
Measured and predicted velocities were in good agreement especially for $3 \mathrm{D}$ calculations. The $2 \mathrm{D}$ prediction tended to underestimate the wind speed at the nacelle anemometer especially for the case of a rotor in operation. In the simulations of Masson and Smaili (2006), a $600 \mathrm{~kW}$ turbine with a radiator below the anemometer was considered, which is similar to the N80. Their results improved slightly by considering the flow through this radiator. However, in our case, this flow has been ignored.

Isocontours of axial velocity around the nacelle with the rotor in operation are presented in Figs. 8 and 9. Two planes containing the

Table 5

Nacelle drag for rotor-off and rotor-on at $15 \mathrm{~m} / \mathrm{s}$ and for mesh 1, 2 and 3 (3D $k-\omega s s t$ ).

\begin{tabular}{lll}
\hline \multirow{2}{*}{ Mesh } & \multicolumn{2}{l}{ Nacelle drag $(\mathrm{N})$} \\
\cline { 2 - 3 } & Rotor-off & Rotor-on \\
\hline 1 & 900.9 & 1026.05 \\
2 & 915.4 & 1055.26 \\
3 & 925.92 & 1089.37 \\
\hline
\end{tabular}

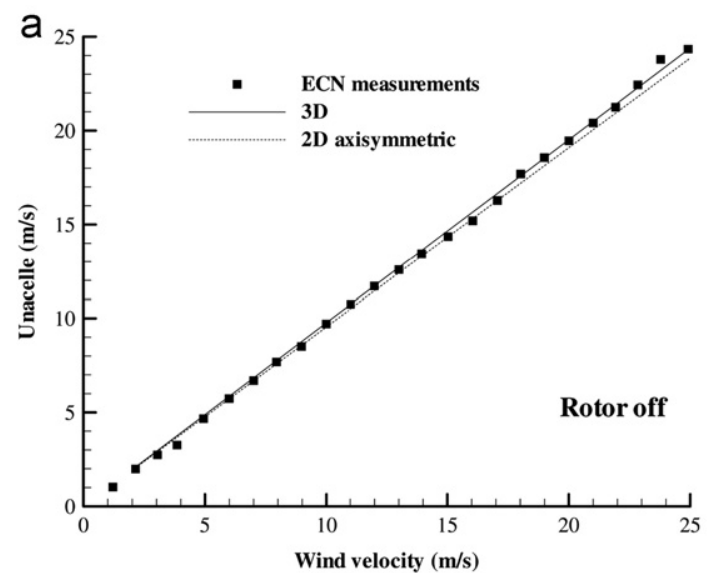

nacelle anemometer were presented: one longitudinal $(x z)$ in the direction of flow and the other transversal $(y z)$. For both wind speeds studied $\left(U_{\infty}=5\right.$ and $20 \mathrm{~m} / \mathrm{s}$ ), recirculation zones were observed. One was small and located just above the top of the nacelle upstream of the radiator. The other was considerably larger and situated at the rear of the nacelle. There were also small areas of high acceleration, where the flow velocity increased by almost $30 \%$ compared to the freestream, which were located mainly in front of the nacelle and on its sides. These accelerations were caused partly by the curvature of the walls. When moving away from the nacelle, the distribution of axial velocity on the lateral $y z$ plane (Figs. 8b and $9 \mathrm{~b}$ ) takes the form of circular contours.

This kind of results can be very practical for turbines manufacturers in order to place the anemometer on the nacelle at the least disturbed location.

Fig. 10 shows the axial velocity profile at the rotor and in the wake at various positions, for both 2D-axisymmetric and 3D calculations. As the ground was not modeled in the axisymmetric formulation, the greatest difference between the two calculations was observed at this boundary. The effect of the presence of the nacelle on the flow led to a large deficit in speed, which was limited to the vicinity of the hub height and weakened along the wake.

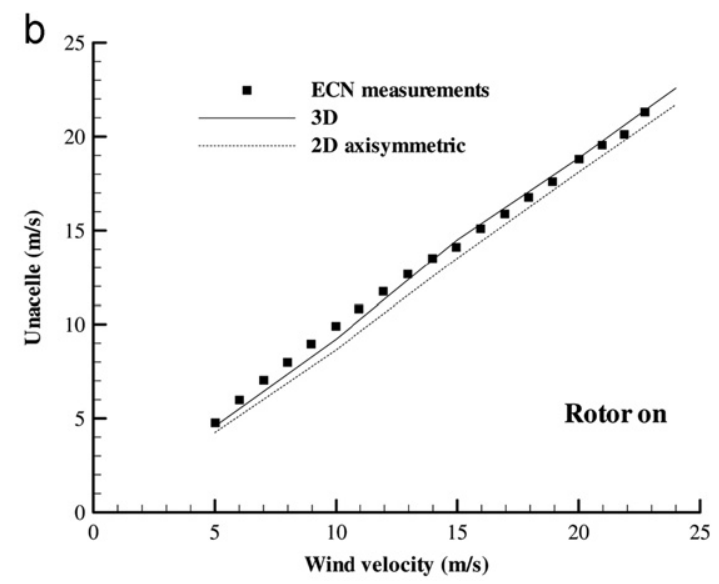

Fig. 7. Wind speed at nacelle anemometer for N80 wind turbine with (a) rotor-off and (b) rotor-on.
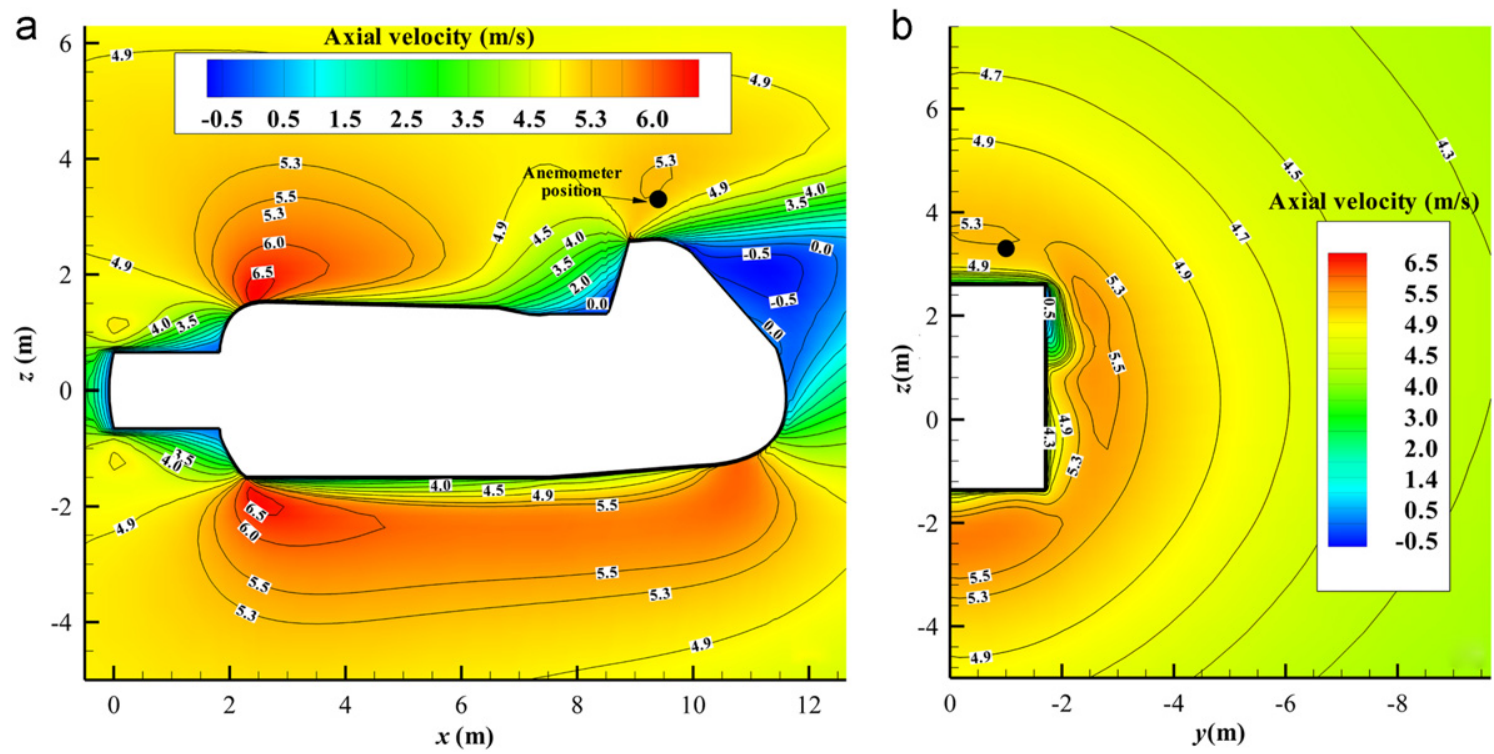

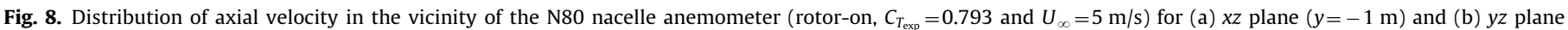
$(x=9.3 \mathrm{~m})$. 

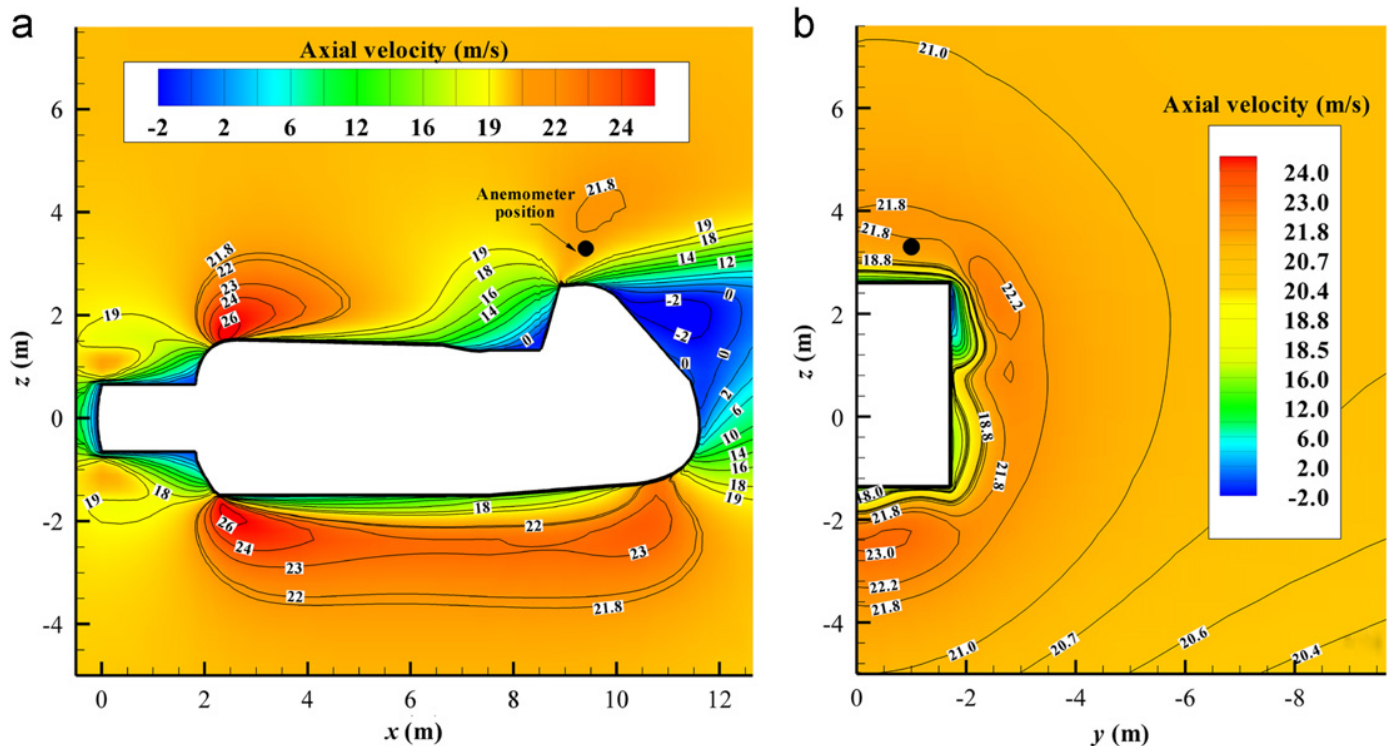

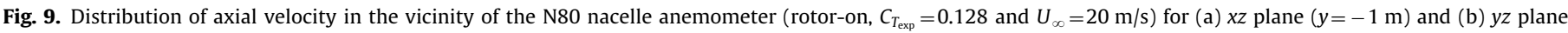
$(x=9.3 \mathrm{~m})$.

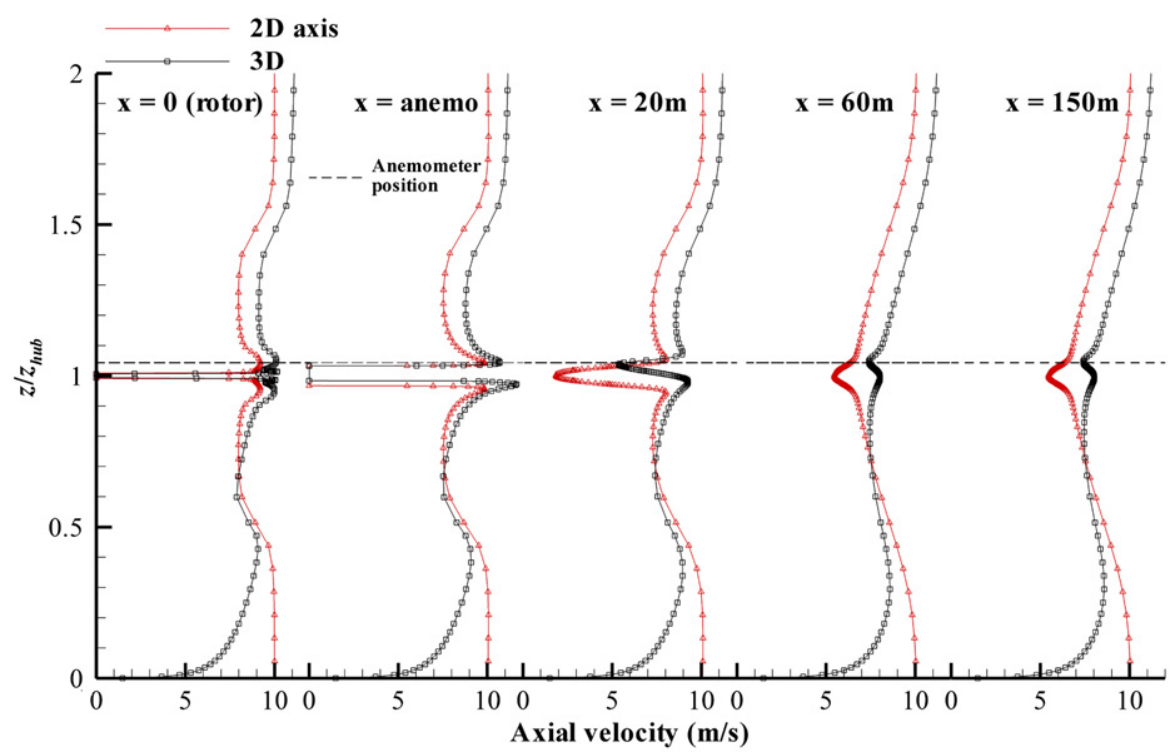

Fig. 10. Axial velocity profile for different downstream positions (rotor-on, $C_{T_{\exp }}=0.689$ and $U_{\infty}=10 \mathrm{~m} / \mathrm{s}$ ).

At hub height and at the nacelle position, the two profiles more or less agreed. In the wake, significant differences were observed between the two profiles. For 3D calculations, the asymmetric shape of the nacelle led a deficit of velocity, which was shifted upward relative to the axis of rotation (i.e. $z / z_{h u b}=1$ ). At $x=150 \mathrm{~m}$, the speed deficit for the two profiles diminished significantly. However, at this distance the 2D-axisymmetric calculations still indicated a significant velocity deficit compared to 3D.

The speed deficit caused by the presence of the rotor was well visible between the heights 0.5 and 1.5 . Both simulations presented some differences but converge quite well at the lower part of the rotor (i.e. $0.5<z / z_{\text {hub }}<0.9$ ). It is well known that the standard $k-\varepsilon$ model underestimate the velocity deficit in the wake (Cabezon et al., 2009). The excessive production of turbulent diffusion is the main cause of this underestimation. Increasing the turbulent dissipation rate in the vicinity of the wind and can greatly improve the predicted results (El Kasmi and Masson, 2008), especially in the far wake. The consideration of the turbulence anisotropy can also improve results (Gomez-Elvira et al., 2005).

Given the proximity of the nacelle with the anemometer, it may be interesting to correctly model the shear resulting from the presence of the wall. A comparison of two types of nacelle wall treatment is shown in Fig. 11. The approach using the standard wall functions was compared with an enhanced treatment, which required a more refined mesh. For rotor-off, the velocity at the nacelle anemometer position was somewhat overestimated for the EWT. For rotor-on, with the EWT the results improved slightly for speeds below $U_{\infty}=16 \mathrm{~m} / \mathrm{s}$; beyond this speed, no significant differences were observed.

Using the $k-\omega$ sst turbulence model of Menter improved the calculation of the axial velocity at the nacelle anemometer position (Fig. 12), especially when the rotor was on. Indeed, one of the strengths of the $k-w$ sst turbulence model is a better treatment of the wall compared to the $k-\varepsilon$ model. 

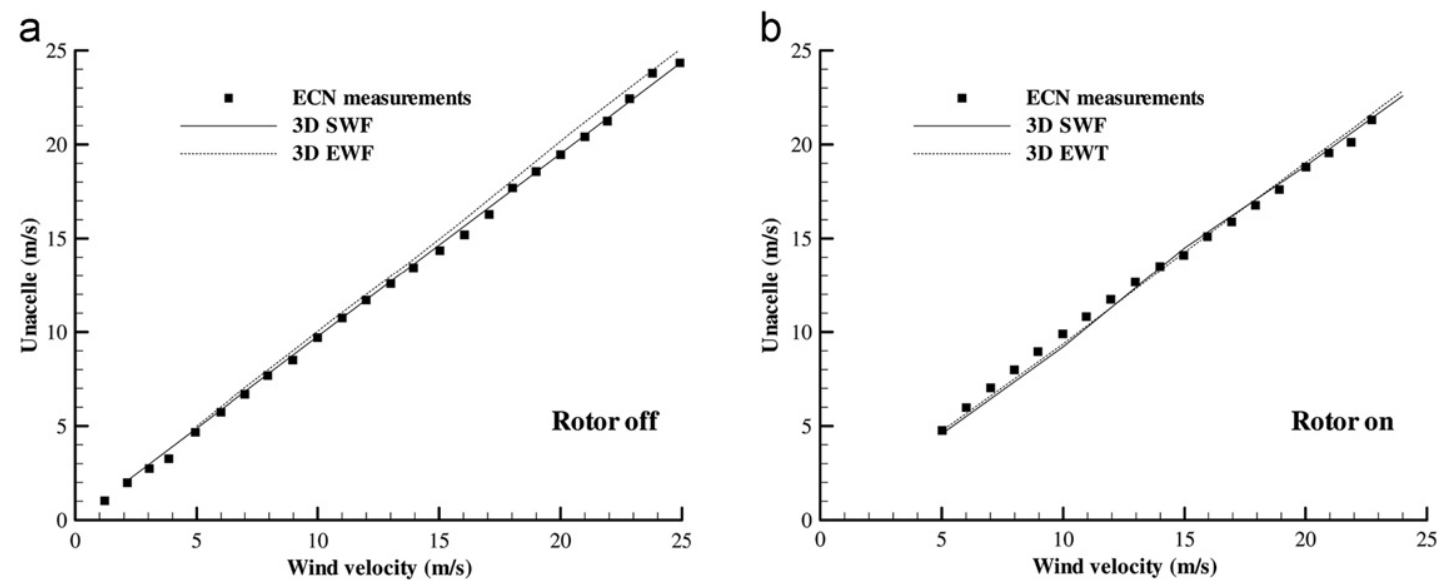

Fig. 11. Effect of wall treatment on the calculation of the velocity at the nacelle anemometer for the N80 wind turbine with (a) rotor-off and (b) rotor-on.
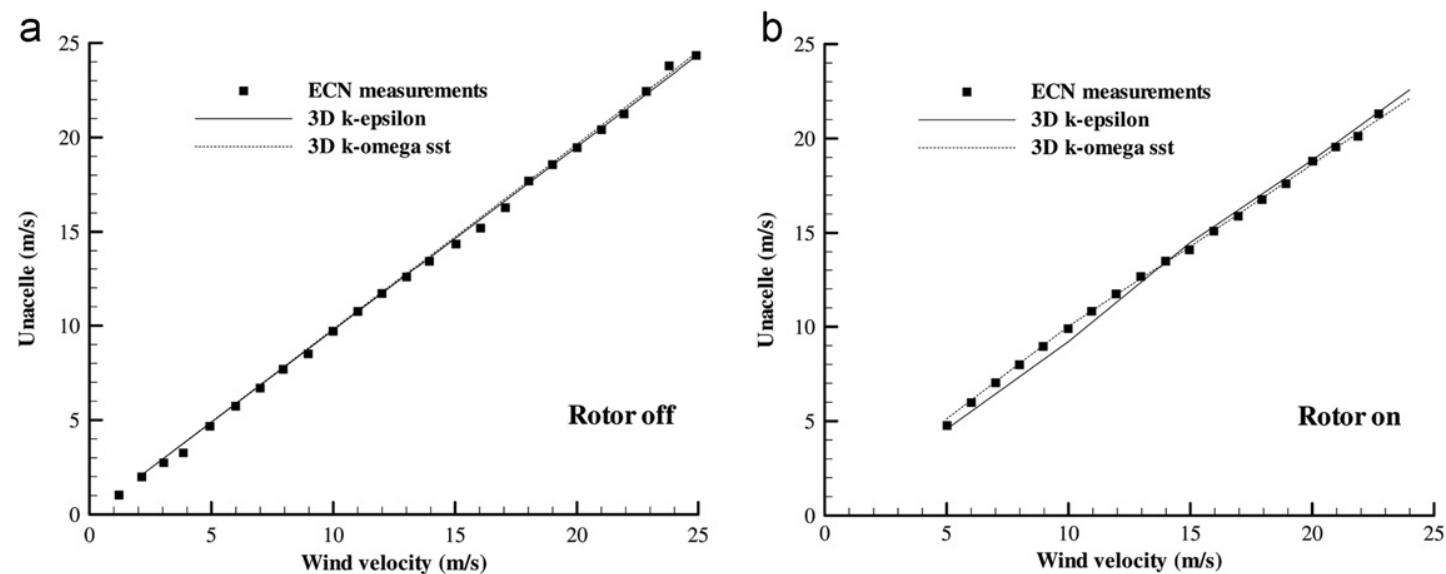

Fig. 12. Wind speed at nacelle anemometer for N80 wind turbine with (a) rotor-off and (b) rotor-on.
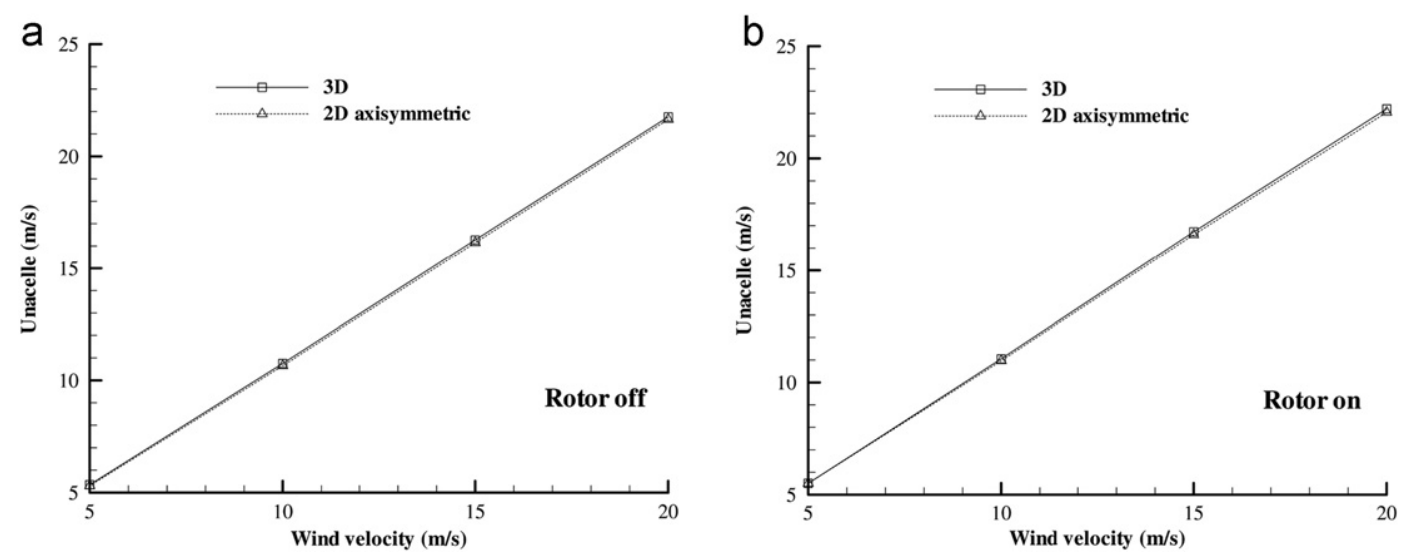

Fig. 13. Velocity at the nacelle anemometer for J48 turbine with (a) rotor-off and (b) rotor-on.

\subsection{Jeumont $\mathrm{J} 48$}

Fig. 13 presents simulations of wind velocity at the nacelle anemometer position for the J48 wind turbine. The 3D and 2D-axisymmetric results were almost identical for both cases: rotor-off and rotor-on. The highly symmetrical geometry of the nacelle relative to the axis of rotation of the rotor was largely responsible to this similarity. Indeed, with such a form the effect of the nacelle was nearly independent of azimuthal position, as illustrated in Fig. 14 where streamlines are drawn around the nacelle. At the front of the nacelle (Fig. 14a) there was an important deceleration of the flow and a stagnation point was observed. Towards the middle, where the geometry of the nacelle has an inflection, an acceleration of the flow was observed. At the rear of nacelle, there is a region of recirculating flow, as can be seen in Fig. 14b.

Fig. 15a and $\mathrm{b}$ shows the horizontal distribution of axial velocity for three vertical positions above the nacelle. The transversal position was taken equal to that of the anemometer, i.e. $y=0$. The largest difference between 2D and 3D results can be found 

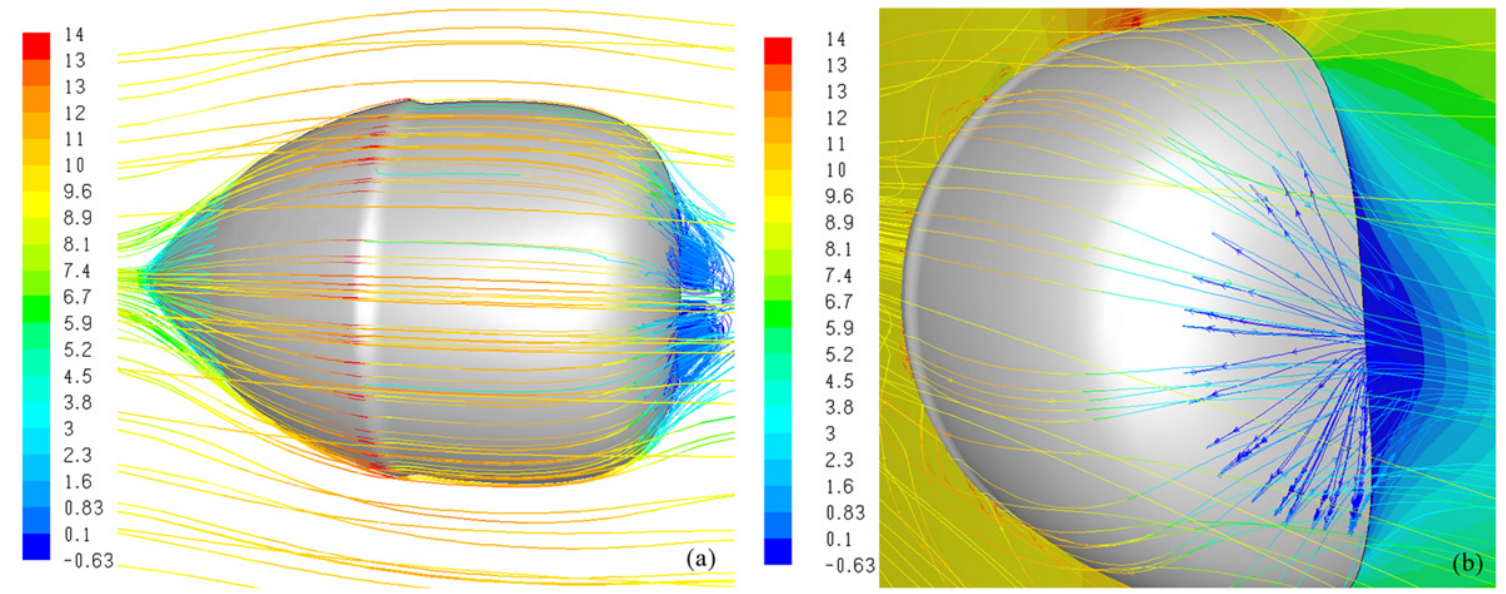

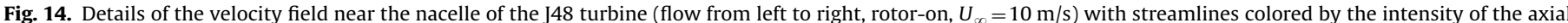

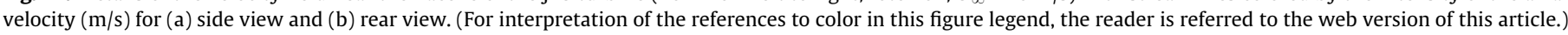
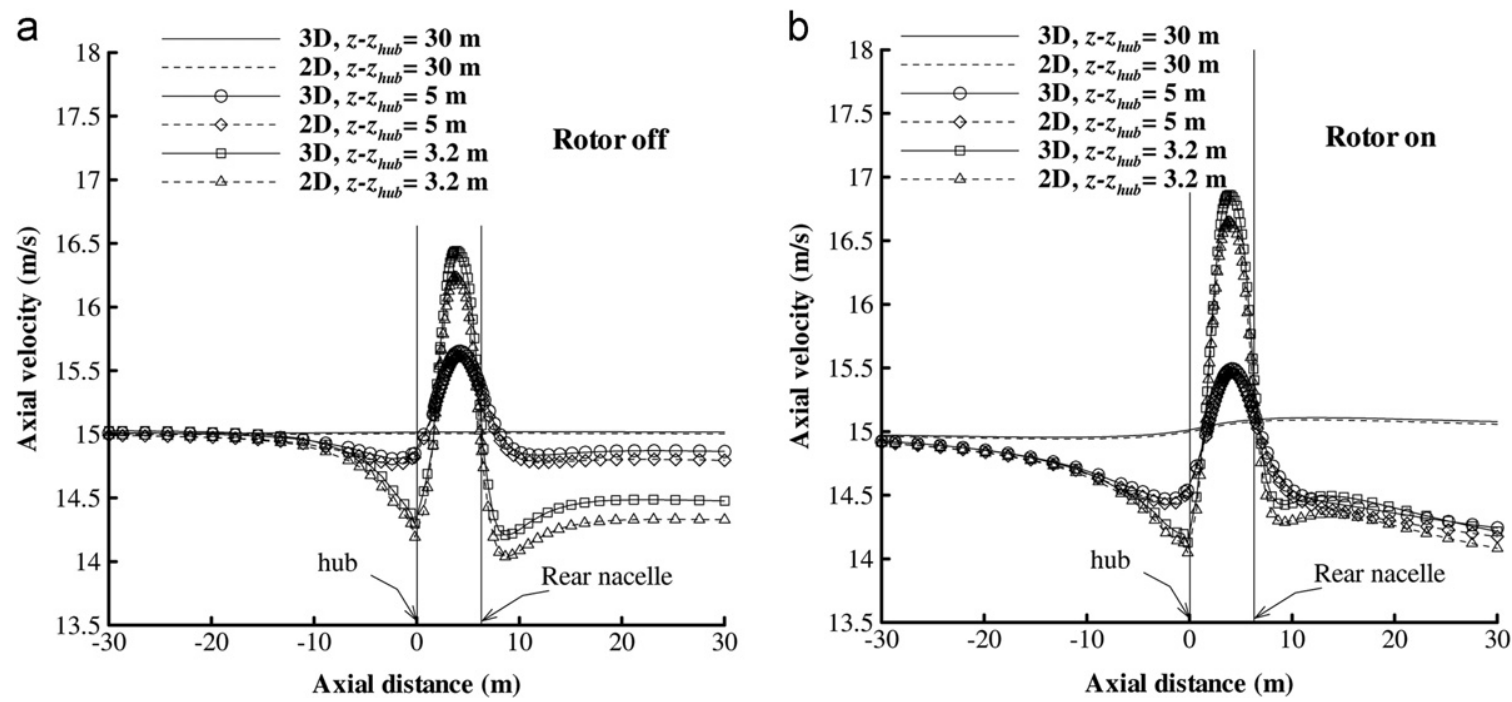

Fig. 15. Axial velocity for different vertical positions above the nacelle of the $J 48$ turbine for (a) rotor-off and (b) rotor-on $\left(U_{\infty}=15 \mathrm{~m} / \mathrm{s}\right)$.

mainly at the rear of the nacelle and for heights close to the nacelle. At $z-z_{\text {hub }}=30 \mathrm{~m}$, the flow was not disturbed by the presence of the nacelle. The effects of the blades were felt, upstream and downstream of the nacelle, even though this position was outside the rotor swept area.

In Fig. 16, the difference between 2D-axisymmetric and 3D calculations for the velocity at nacelle anemometer position is presented for the two different nacelle geometries. This difference is evaluated as

$D_{2 \mathrm{D}-3 \mathrm{D}}=\frac{\left|U_{\text {nacelle }}(3 D)-U_{\text {nacelle }}\left(2 D_{\text {axi }}\right)\right|}{U_{\infty}}$

For a symmetric nacelle (J48), the difference between 2D-axisymmetric and 3D calculations was very small, around $2 \%$. However, for a nacelle with a complex geometry such as the $\mathrm{N} 80$, the difference increased to about $8 \%$ for rotor-on and $12 \%$ for rotor-off. This showed the importance of choosing the solver according to the geometry of the nacelle.

Often turbine manufacturers offer several tower heights so it may be interesting to analyze the effect of hub height on the nacelle anemometer. To this end, the J48 nacelle was chosen and 3D simulations with different hub heights have been carried out. A single velocity profile at the inlet was selected and the reference height was $46 \mathrm{~m}(H / D=0.958)$. Fig. 17 shows the velocity at the

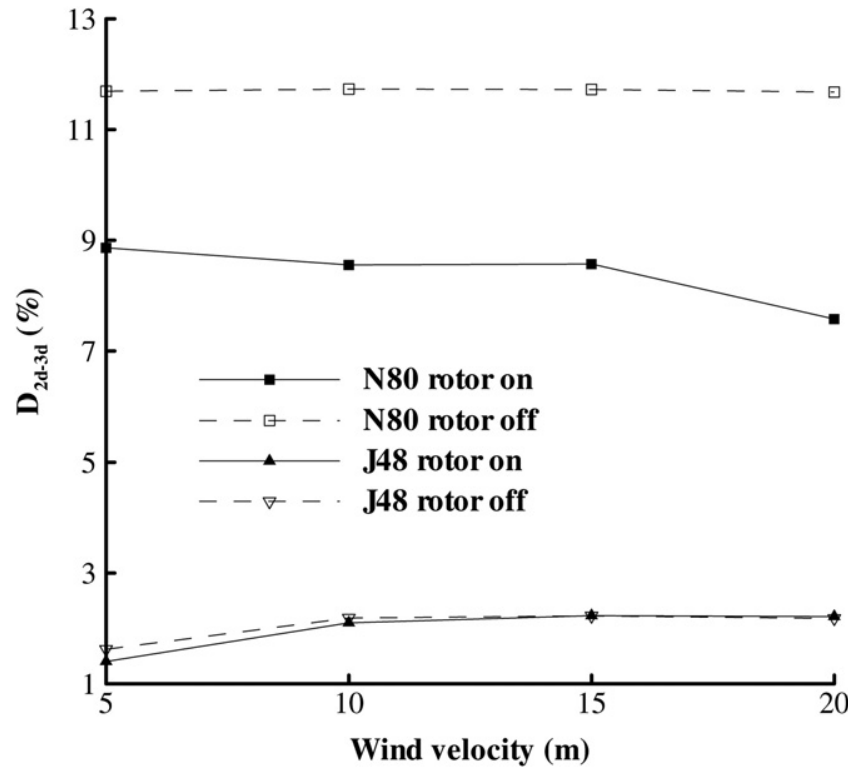

Fig. 16. Difference between 2D-axisymmetric and 3D calculations of the wind speed at the anemometer for two types of nacelle. 

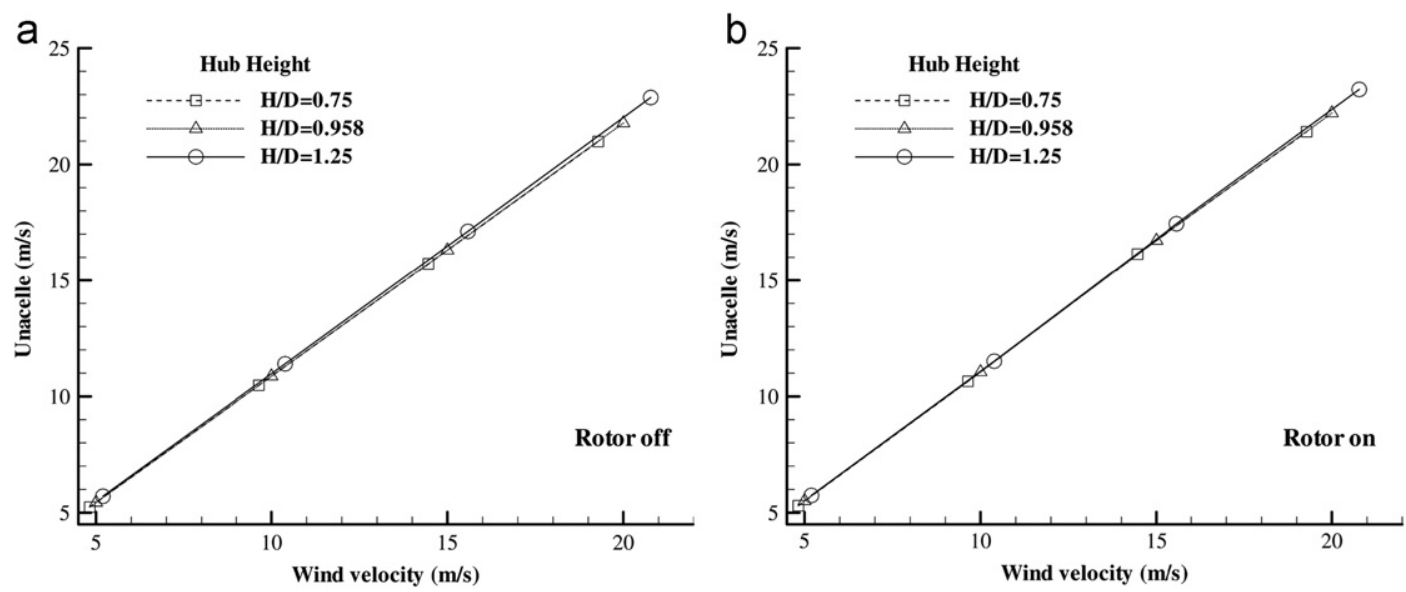

Fig. 17. Hub height effect on the J48 nacelle anemometer for (a) rotor-off and (b) rotor-on.

nacelle anemometer position for three different hub heights $(H / D=0.75,0.958$ and 1.25$)$ and with both the rotor-off and rotoron. Obviously, the speed at the nacelle anemometer increased with hub height. For a stopped rotor, the average increase in the velocity at the nacelle anemometer position was about $8.88 \%$ for low wind speed $(5 \mathrm{~m} / \mathrm{s})$ and about $9.04 \%$ for high wind speed $(20 \mathrm{~m} / \mathrm{s})$. The effect was somewhat dampened with the rotor in operation and was reduced to $8.39 \%$ for low wind speed and $8.49 \%$ for high wind speed. These increases in speed were slightly higher than what was predicted by the logarithmic profile $(7.75 \%)$ in the absence of obstacles. Finally, the slope and offset of the curves $U_{\text {nacelle }} / U_{\infty}$ remain insensitive with hub height variations.

\section{Conclusions}

Two-dimensional axisymmetric and three-dimensional numerical simulations of flow around two horizontal-axis wind turbines, with different nacelle geometries, were conducted. The analysis was mainly focused on the rotor and its near wake around the nacelle to evaluate the relationship between the freestream wind speed and that measured at the position of the nacelle anemometer.

The geometry of the nacelle was numerically represented as faithfully as possible. The rotor was modeled using the actuator disk concept. Two approaches were used to evaluate the associated pressure jump, depending on the availability of airfoil aerodynamic characteristics. A neutral atmospheric boundary layer was modeled for a more realistic representation of the flow field.

The calculated nacelle anemometry correlations agreed well with experimental data especially for 3D simulations. Given the proximity of the anemometer to the nacelle, the effect of a more sophisticated law of the wall was investigated. However, the great computational cost that accompanied this technique and the slight improvement in results led us to not recommend this law of the wall for the nacelle. However, results were improved without an important additional computational cost using the $k-\omega$ sst turbulence model instead of the classic $k-\varepsilon$.

It was further shown that differences between 2D and 3D results largely depend on the shape of the nacelle. Indeed, it was demonstrated that for the J48 2D-axisymmetric calculations were appropriate; this was not the case for the N80 where the complex geometry of the nacelle generated three-dimensional effects, which required a 3D approach.

The importance of hub height effects on nacelle anemometry was analyzed by varying the height of the turbine. By moving the
J48 nacelle from $0.75 D$ to $1.25 D$, the predicted speed at the anemometer position was slightly higher than what is predicted by the logarithmic profile and the slope of the $U_{\text {nacelle }} / U_{\infty}$ curves remain almost unchanged.

The analysis of physical parameters such as terrain topography, which can significantly influence the relationship $U_{\text {nacelle }} / U_{\infty}$ is reserved for future works. A more realistic representation of the rotor to capture the phenomena associated with unsteadiness and three-dimensional rotation of the blades, such as tip vortex structures, is also recommended to improve modeling of the rotornacelle interaction.

\section{Acknowledgments}

This study received support from the NSERC Wind Energy Strategic Network and from the Canada Research Chair Program.

\section{References}

Antoniou, I., Pedersen, T.F., 1997. Nacelle Anemometry on a 1 MW Wind Turbine: Comparing the Power Performance Results by Use of the Nacelle or Mast Anemometer. RISØ-R-941, RISØ National Laboratory, Denmark.

Blocken, B., Stathopoulos, T., Carmeliet, J., 2007. CFD simulation of the atmospheric boundary layer: wall function problems. Atmospheric Environment 41 (2), 238-252.

Brodeur, P., Masson, C., 2008. Numerical site calibration over complex terrain. Journal of Solar Energy Engineering 130 (3), 031020-031021.

Cabezon, D., Sanz, J., Marti, I., Crespo, A., 2009. CFD modeling of the interaction between the surface boundary layer and rotor wake comparaison of results obtained with different turbulence models and mesh strategies. In: Proceedings of the European Wind Energy Conference, Marseille.

Cebeci, T., Bradshaw, P., 1977. Momentum Transfer in Boundary Layers. Hemisphere Publishing Corporation, New York.

Celik, I.B., Ghia, U., Roache, P.J., Freitas, C.J., Coleman, H., Raad, P.E., 2008. Procedure for estimation and reporting of uncertainty due to discretization in CFD applications. Journal of Fluids Engineering 130 (7), 078001-078004.

Crespo, A., Hernández, J., Frandsen, S., 1999. Survey of modelling methods for wind turbine wakes and wind farms. Wind Energy 2 (1), 1-24.

Crespo, A., Manwel, F., Moreno, D., Fraga, E., Hernandez, J., 1985. Numerical analysis of wind turbine wakes. In: Proceedings of the Workshop on Wind Energy Application, Delphi, Greece.

Eecen, P.J., Verhoef, J.P., 2007. EWTW Meteorological Database Description June 2003-May 2007. ECN-E-07-041, ECN Windenergy, Netherlands.

El Kasmi, A., Masson, C., 2008. An extended $k-\varepsilon$ model for turbulent flow through horizontal-axis wind turbines. Journal of Wind Engineering and Industrial Aerodynamics 96 (1), 103-122.

Fluent Inc., 2005. Fluent 6.2 User's Guide, Lebanon, USA

Frandsen, S., Sørensen, J.N., Mikkelsen, R., Pedersen, T.F., Antoniou, I., Hansen, K., 2009. The generics of wind turbine nacelle anemometry. In: Proceedings of the European Wind Energy Conference, Marseille.

Gasset, N., Poitras, G.J., Gagnon, Y., Brothers, C., 2005. Study of atmospheric boundary layer flows over a coastal cliff. Wind Engineering 29 (1), 3-24. 
Gomez-Elvira, R., Crespo, A., Migoya, E., Manuel, F., Hernandez, J., 2005. Anisotropy of turbulence in wind turbine wakes. Journal of Wind Engineering and Industrial Aerodynamics 93 (10), 797-814.

Hargreaves, D.M., Wright, N.G., 2007. On the use of the $k-\varepsilon$ model in commercial CFD software to model the neutral atmospheric boundary layer. Journal of Wind Engineering and Industrial Aerodynamics 95 (5), 355-369.

Hefny, M.M., Ooka, R., 2009. CFD analysis of pollutant dispersion around buildings: effect of cell geometry. Building and Environment 44 (8), 1699-1706.

Hoerner, S.F., 1965. Resistance a L'avancement dans les Fluides. Gauthier-Villars, Paris.

Hunter, R., Pedersen, T.F., Dunbabin, P., Antoniou, I., Frandsen, S., Klug, H., Albers, A. Lee, W.K., 2001. European Wind Turbine Testing Procedure Developments, Task1: Measurement Method to Verify Wind Turbine Performance Characteristics. RisoR-1209, Riso National Laboratory, Roskilde.

IEC CD61400-12-2, 2008. Wind Turbines Part 12-2: Power Performance of Electricity Producing Wind Turbines Based on Nacelle Anemometry. 88/325/CD.

Launder, B.E., Spalding, D.B., 1974. The numerical computation of turbulent flows. Computer Methods in Applied Mechanics and Engineering 3 (2), 269-289.

Masson, C., Smaili, A., 2006. Numerical study of turbulent flow around a wind turbine nacelle. Wind Energy 9 (3), 281-298.

Menter, F.R., 1994. Two-equation eddy-viscosity turbulence models for engineering applications. AIAA Journal 32 (8), 1598-1605.

Migoya, E., et al., 2007. Comparative study of the behavior of wind-turbines in a wind farm. Energy 32 (10), 1871-1885.
Prospathopoulos, J., Voutsinas, S.G., 2006. Implementation issues in 3D wind flow predictions over complex terrain. Transactions of the ASME. Journal of Solar Energy Engineering 128 (4), 539-553.

Richards, P.J., Hoxey, R.P., 1993. Appropriate boundary conditions for computational wind engineering models using the $k$-epsilon; turbulence model. Journal of Wind Engineering and Industrial Aerodynamics 46-47, 145-153.

Roache, P.J., 1994. Perspective: a method for uniform reporting of grid refinement studies. Journal of Fluids Engineering, Transactions of the ASME 116 (3), 405-413.

Smaili, A., Masson, C., 2004. On the rotor effects upon nacelle anemometry for wind turbines. Wind Engineering 28 (6), 695-714.

Smith, B., Link, H., Randall, G., McCoy, T., 2002. Applicability of nacelle anemometer measurements for use in turbine power performance tests: Preprint, (AWEA). In: Proceedings of the WindPower 2002 Conference, Portland, Oregon, 22 pp.

Snel, H., 1998. Review of the present status of rotor aerodynamics. Wind Energy 1 (S1), 46-69.

Sørensen, J.N., Myken, A., 1992. Unsteady actuator disc model for horizontal axis wind turbines. Journal of Wind Engineering and Industrial Aerodynamics 39 (1-3), 139-149.

Vermeer, L.J., Sørensen, J.N., Crespo, A., 2003. Wind turbine wake aerodynamics. Progress in Aerospace Sciences 39 (6-7), 467-510.

Wilcox, D.C., 1993a. Comparison of two-equation turbulence models for boundary layers with pressure gradient. AIAA Journal 31 (8), 1414-1421.

Wilcox, D.C., 1993b. Turbulence Modeling for CFD. DCW Industries, La Canada, Calif.

Zahle, F., Sørensen, N.N., 2011. Characterization of the unsteady flow in the nacelle region of a modern wind turbine. Wind Energy 14, 271-283. 